\title{
Precipitation Strengthening of Fine-Wire of the Au-1wt\%Ti Alloy - 10 Years at Room Temperature
}

\author{
Giles Humpston \\ GEC Marconi Materials Technology, Caswell, Towcester, Northamptonshire, NN12 8EQ, UK
}

One of the most significant developments in gold technology in recent years has been 990 gold $(1,2)$. This is a precipitation strengthening alloy of gold containing $1 \%$ of titanium by weight. This addition is found to substantially harden the gold and improve its wear resistance without adversely affecting its hue or workability, which makes it extremely attractive for high carat jewellery and, as a fine wire, for interconnects to microelectronic devices.

The metallurgical strengthening process in 990 gold has been studied in great detail for the alloy in both bulk and fine dimensions (3-5). One observation arising from the work on fine wire was that if left in an ambient environment at room temperature, precipitation strengthening occurs. One possible explanation for this phenomenon is that the precipitation process is being driven by the stored energy imparted to the alloy on cold working to a fine wire, just $25 \mu \mathrm{m}$ in diameter. This explanation is consistent with the observation that pure gold recovers and recrystallizes at room temperature after being subjected to mechanical cold work.

It is now ten years since the sample of fine wire was prepared and, during this time, its tensile strength and elongation to failure have been measured regularly. The data, presented in Figure 1, show that the alloy has precipitation strengthened and is now over-ageing in the classical manner. Over the same period the elongation to failure of the wire has increased slightly from 1.5 to $3 \%$, on a $25 \mathrm{~mm}$ gauge length.

Extrapolation of the graph in Figure 1 suggests that the next measurement is due at about 300,000 hours; that is, in approximately 25 years. The author hopes to report the result in a subsequent issue of Gold Bulletin.

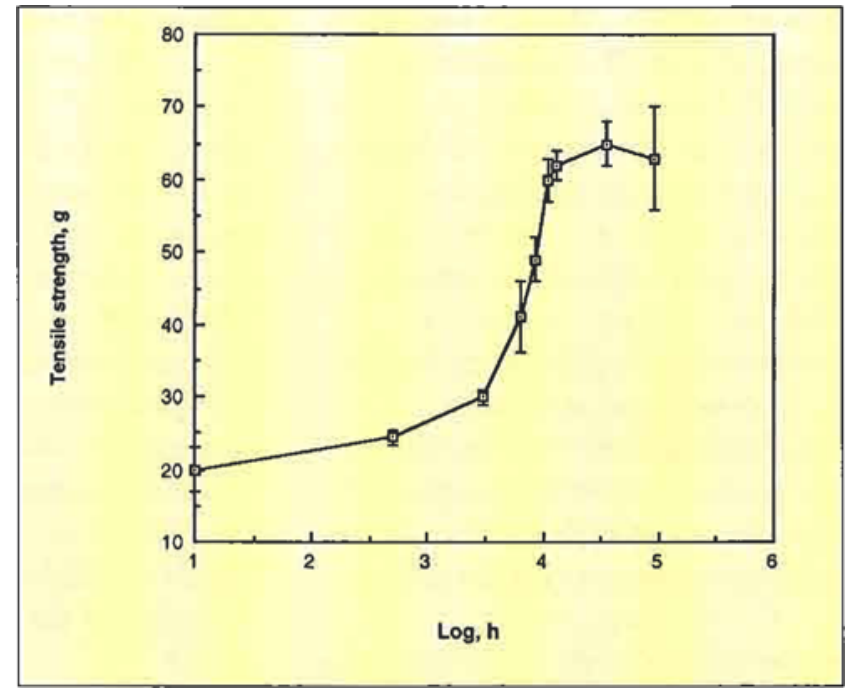

Figure 1 Ageing of 990 gold

\section{ACKNOWLEDGEMENT}

The development work on 990 gold was funded by World Gold Council.

\section{REFERENCES}

1 A.M. Tasker, Aurum, 1988, 34, 62

2 G. Gafner, Gold Bull., 1989, 22, 112

3 Entire issue (four articles), Gold Technol., 1992, 6, pp. $1-12$

4 G. Humpston and D.M. Jacobson, Gold Bull., 1992, 25, 132

5 D.M. Jacobson, M.R. Harrison and S.P.S. Sangha, Gold Bull., 1996, 2, 95 